\title{
A ação pública de adaptação da agrícultura à mudança climática no Nordeste semiárido brasileiro
}

organizadores

ERIC SABOURIN I LUCIA MARIZY RIBEIRO OLIVEIRA

FRÉDÉRIC GOULET | EDUARDO SÁVIO MARTINS

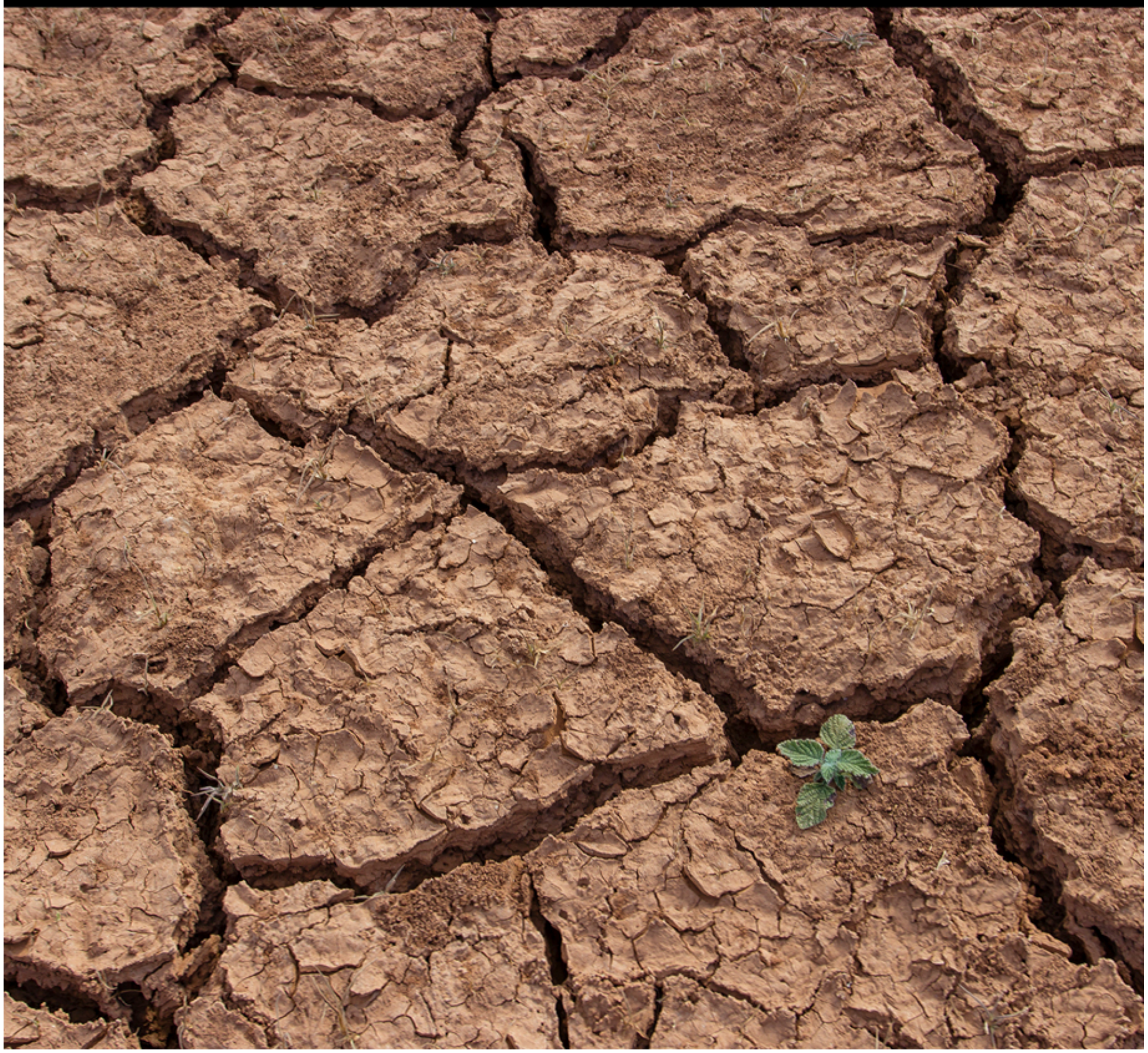




\section{A ação pública de adaptação da agricultura à mudança climática no Nordeste semiárido brasileiro}

organizadores

ERIC SABOURIN | LUCIA MARIZY RIBEIRO OLIVEIRA

FRÉDÉRIC GOULET | EDUARDO SÁVIO MARTINS

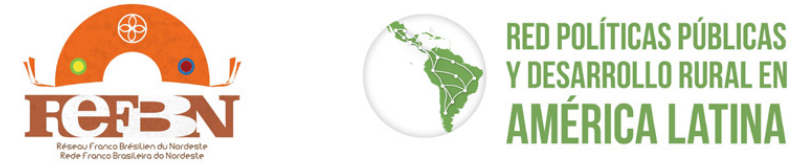

Rio de Janeiro, 2021

\section{[E]e-papers}


(C) Eric Sabourin, Lucia Marizy Ribeiro Oliveira, Frédéric Goulet e Eduardo Sávio Martins/E-papers Serviços Editoriais Ltda., 2021.

Todos os direitos reservados a Eric Sabourin, Lucia Marizy Ribeiro Oliveira, Frédéric Goulet e Eduardo Sávio Martins/E-papers Serviços Editoriais Ltda.

ISBN 978-65-87065-25-0

Rede Franco-Brasileira pelo Desenvolvimento Sustentável no Semiárido do Nordeste (ReFBN)

Rede Políticas Públicas e Desenvolvimento Rural na América Latina (PP-AL)

Ministério Francês de Relaçóes Exteriores - Instituto Francês no Brasil

Revisão

Nancy Soares

Diagramação

Michelly Batista

Imagem de capa

Brasil2/IStockPhoto

Uma publicação da Editora E-papers

http://www.e-papers.com.br

E-papers Serviços Editoriais Ltda.

Av. das Américas, 3200, bl. 1, sala 138

Barra da Tijuca - Rio de Janeiro

CEP 22640-102

Rio de Janeiro, Brasil

CIP-Brasil. Catalogação na fonte

Sindicato Nacional dos Editores de Livros, RJ

\section{A153}

A ação pública de adaptação da agricultura à mudança climática no nordeste semiárido brasileiro / organização Eric Sabourin ... [et al.]. - 1. ed. - Rio de Janeiro : E-papers, 2021.

282 p. : il. ; $23 \mathrm{~cm}$.

Inclui bibliografia

ISBN 978-65-87065-25-0

1. Agricultura de regiôes áridas - Brasil, Nordeste. 2. Mudanças climáticas - Aspectos ambientais. 3. Climatologia agrícola - Brasil. 4. Agricultura e Estado - Brasil. 5. Desenvolvimento rural - Brasil. I. Sabourin, Eric.

$21-73200$

CDD: 338.18813

CDU: 338.43.02(812/813)

Camila Donis Hartmann - Bibliotecária - CRB-7/6472 


\title{
CAPÍTULO 10
}

\section{As políticas de promoção dos bioinsumos no Brasil. Entre alternativas e alinhamentos}

\author{
Frédéric Goulet
}

A redução do uso de insumos químicos é um dos pilares do desenvolvimento da agricultura orgânica e da agroecologia. Em todos os agrossistemas, em todas as regiôes, para todos os tipos de produtores ou consumidores, a agricultura ecológica é acima de tudo a agricultura que utiliza menos, ou náo utiliza mais insumos químicos, especialmente agrotóxicos. O mercado, com a crescente demanda por alimentos saudáveis, é uma força fundamental para que os produtores reduzam o uso desses produtos. Mas o Estado, através das políticas públicas que concebe e implementa, é também um ator-chave na promoção de uma descontinuidade (STEGMAIER; KUHLMANN; VISSER, 2014) na relação entre a agricultura contemporânea e os agrotóxicos. Mesmo que essas políticas nem sempre sejam bem-sucedidas (GUICHARD et al., 2017), elas contribuem para definir diretrizes e instrumentos para restringir o acesso dos agricultores aos agrotóxicos e promover alternativas tecnológicas. Sobre este último ponto, as alternativas biológicas constituíram um pacote tecnológico particularmente promissor nos últimos anos. $\mathrm{O}$ uso do controle biológico não é novo em si mesmo (ALTIERI et al., 1997), e os agricultores brasileiros, particularmente no Nordeste, têm desempenhado um papel pioneiro na produção caseira e no uso de caldos, misturas e outros preparados (ALBIERO et al., 2015). Mas, nos últimos anos, as iniciativas públicas se intensificaram para promover o desenvolvimento desses produtos (AULAGNIER; GOULET, 2017; GOULET; HUBERT, 2020, GOULET et al., 2020). Este é notavelmente o caso do Brasil, onde desde 2018 foram desenvolvidas e implementadas políticas específicas para incentivar o desenvolvimento de bioinsumos, uma categoria que inclui tanto o controle biológico quanto os fertilizantes biológicos. Neste capítulo, analisamos a gênese e o desenho destas políticas e como elas consideram a relação entre estes insumos biológicos e os insumos químicos amplamente utilizados. Em particular, mostramos que estas políticas ajudam a 
organizar uma coexistência e alinhamento entre estas tecnologias, dentro de uma transição (GEELS, 2002) que permite aos atores do regime agroindustrial adaptar suas práticas e posiçóes.

Esta reflexão se baseia em pesquisas realizadas no Brasil entre 2018 e 2020, que analisaram os motores e as modalidades do surgimento de um Programa Nacional de Bioinsumos liderado pelo Ministério da Agricultura do Estado Federal em Brasília. Realizamos entrevistas semidiretivas com funcionários do Mapa que contribuíram para a elaboração e implementaçáo deste programa, assim como com uma ampla gama de atores relacionados aos insumos biológicos: cientistas da Embrapa, funcionários da Anvisa, órgãos representativos dos agricultores, como os Grupos Associados de Agricultura Sustentável, e ONGs que promovem a agroecologia. Também realizamos observaçóes etnográficas durante eventos organizados em torno da construção e implementação do Programa Nacional de Bioinsumos. Finalmente, realizamos uma análise de conteúdo de documentos institucionais produzidos por administraçóes ou organizaçóes relacionadas aos bioinsumos ou agrotóxicos no Brasil.

\section{A criação de uma nova categoria: os bioinsumos}

A questão do desenvolvimento e definição de alternativas tecnológicas aos agrotóxicos não é um assunto novo no Brasil. Ao contrário, a novidade ocorrida no final de 2010 foi uma nova infraestrutura para classificar essas tecnologias (BOWKER; LEIGH STAR, 1999), permitindo que tecnologias heterogêneas fossem agrupadas.

\section{Primeiras convergências no âmbito das agriculturas alternativas}

Os primeiros desenvolvimentos dentro do Estado brasileiro ocorreram nos anos 2000, primeiramente no âmbito das políticas de promoção da agricultura orgânica, visando em particular facilitar o registro de produtos de origem natural para a saúde vegetal ou nutriçáo a partir de 2009. Mas o verdadeiro começo foi feito com o estabelecimento do Plano para Agroecologia e Agricultura Orgânica (PLANAPO), administrado pela Comissáo Nacional de Agroecologia e Agricultura Orgânica (CNAPO). Desde sua primeira versão (2013-2015), ele incentiva o desenvolvimento de alternativas aos agrotóxicos no Brasil. Em interaçáo com movimentos sociais, o CNAPO propõe, através de seu Grupo de Trabalho "Pesticidas", um Programa Nacional para a Redução de Pesticidas (PRONARA). A ênfase é colocada na necessidade de promover a adoçáo de métodos alternativos de produção e na necessidade de fomentar a emancipação dos agricultores dos insumos externos e das empresas que os comercializam. No âmbito da abordagem 
holística desenvolvida pelo movimento de agroecológico, não são somente os agrotóxicos que estão sendo questionados, mas também todo o sistema agroindustrial que prejudicaria o meio ambiente e a sobrevivência dos pequenos produtores rurais. Sem apoio suficiente na Câmara parlamentar, e diante da influência da bancada ruralista, o Pronara nunca verá a luz do dia, mas a ideia de promover alternativas tecnológicas está ganhando terreno. De fato, está consolidada no Planapo 2 (2016-2019), na forma de um novo termo: bioinsumos. O funcionário encarregado da elaboração do plano, que também chefia a Coordenação Nacional de Agroecologia e Agricultura Orgânica dentro do ex- Ministério do Desenvolvimento Agrário (MDA), procura então impulsionar a questáo dos insumos alternativos. Naquela época, a questão dos insumos era objeto de debate entre os dois "irmãos inimigos" da agricultura orgânica e da agroecologia, ambas questionando o modelo agroindustrial, mas com certas variantes. Ele explica:

A gente estava num processo extremamente sensível, com a sociedade, para juntar agroecologia com produção orgânica. Na visão de muita gente do movimento agroecológico, a palavra insumos está associada ao agronegócio. Então, você explicitar a questáo insumos era algo difícil. Aí, você vai ver lá no PLANAPO I que a gente usa assim: "Desenvolvimento de tecnologias apropriadas" (...). Eu falei - "Gente, vamos fazer uma coisa? Vamos nos pegar pelos consensos, e deixar os dissensos para gente brigar aos poucos; ao longo do tempo ir construindo".

Enquanto o termo "insumos" só estava associado no Planapo 1 com a ideia de "insumos externos", ele entáo propôs para o Planapo 2 a noção de bioinsumos, que ele descobriu na reuniáo da Comissão Interamericana de Agricultura Orgânica liderada pelo Instituto Interamericano de Cooperaçáo Agrícola (IICA), na qual ele representa o Estado brasileiro. Ele sabe que a Argentina acaba de lançar um programa para apoiar os bioinsumos, e considera o conceito particularmente eficaz:

Bioinsumos ajudava a vender, porque o bio era uma coisa que ajudava a pegar quem não conhecia o processo. (...) A gente assumiu de chamar o programa de bioinsumos como se fosse um nome fantasia do bio, um pouco associado a algo que serve para agricultura de base ecológica e tal. E não necessariamente que seja restrito. Para a gente não fechar.

Além dessa tentativa de alinhar essas duas correntes da agricultura ecológica, esta nova noção na paisagem brasileira introduz um segundo tipo de alinhamento, aquele entre produtos de controle e produtos fertilizantes. No entanto, 
a noção permanece associada principalmente aos insumos de controle biológico: no livro publicado em 2017 que apresenta o PNAPO, o capítulo dedicado à regulamentaçáo dos bioinsumos não menciona os biofertilizantes em nenhum ponto (MACÊDO JORGE; VAZ DE SOUZA, 2017). Mas, enquanto o Planapo 2 estava prestes a ser lançado em 2016, o impulso político que havia permitido uma crescente consideração de alternativas aos agrotóxicos parou de repente em 2016. Dilma Roussef, que havia apoiado alternativas ao agronegócio, foi demitida em 2016 a favor de Michel Temer. Temer forma um novo governo de alternância, ancorado à direita, que coloca um claro fim às políticas de apoio às alternativas agroecológicas.

\section{A chegada dos bioinoculantes}

Em 2019, a chegada de Jair Bolsonaro ao poder confirma essa tendência, apoiando claramente o desenvolvimento do agronegócio. Entretanto, foi durante seu primeiro ano de mandato que a administração Bolsonaro decidiu relançar um elemento em particular do Planapo 2: aquele associado aos bioinsumos. A ideia é simples: o objetivo é tanto promover a agricultura orgânica para que ela possa emergir de um nicho de mercado e ajudar o Brasil a fortalecer sua posiçáo de exportaçáo neste setor quanto garantir que o agronegócio também se beneficie de inovaçôes tecnológicas e biotecnológicas no campo dos insumos biológicos. O conceito de bioinsumos, que havia acabado de surgir no contexto da promoçáo de alternativas ao agronegócio, tornou-se entáo uma das pedras angulares na promoçấo de uma nova agricultura baseada na diretriz da bioeconomia (sobre o desenvolvimento deste conceito na América Latina, ver DELVENNE; HENDRICKX, 2013). Em seu discurso para o lançamento do Programa Nacional de Bioinsumo, a Ministra da Agricultura disse o seguinte:

"Com isso nós realmente estaríamos entrando (...) na bioeconomia tão falada, essa bioeconomia, que a agricultura brasileira agora entra de fato, com base naquilo que nós queremos da agricultura do futuro".

Se a primeira abordagem dos bioinsumos tivesse aberto o caminho para o agrupamento de produtos de controle e fertilizantes dentro da mesma categoria, esta dinâmica seria aqui afirmada em escala maciça, desta vez integrando bioinoculantes, um conjunto de tecnologias pertencentes à categoria de biofertilizantes que tem sido um pilar do crescimento do agronegócio brasileiro desde o final dos anos 1990. Os bioinoculantes surgiram no Brasil em meados dos anos 1990, em laboratórios públicos e startups biotecnológicas, com o objetivo de aperfeiçoar um mecanismo simbiótico natural para economizar a entrada de fertilizantes 
nitrogenados. Plantas da família das leguminosas, como a soja, desenvolvem uma simbiose com fungos do solo, graças a uma bactéria que aprisiona o nitrogênio atmosférico no solo. Os pesquisadores isolaram, selecionaram e melhoraram as cepas bacterianas no laboratório, e depois conseguiram fixá-las nas sementes plantadas no solo. Em apenas algumas décadas, a indústria de bioinoculantes tornou-se um dos pilares do setor de insumos agrícolas no Brasil.

Em um momento em que o Estado está relançando sua iniciativa sobre bioinsumos, a integração destes biofertilizantes e sua história de sucesso está tornando-os o novo pilar desta categoria, mesmo que os biofertilizantes tenham estado até então em desvantagem, em favor de alternativas aos agrotóxicos. Este movimento, impulsionado pelo Ministério da Agricultura, está sendo seguido por outras organizaçôes públicas e privadas. Este é o caso em particular da Embrapa, que está organizada em suas principais linhas de pesquisa em torno de carteiras nas quais estão envolvidos pesquisadores de diferentes centros do país. Até 2019, entre as cerca de quarenta carteiras, a Embrapa tinha duas carteiras separadas dedicadas, respectivamente, ao controle biológico e à fixação atmosférica de nitrogênio. Alinhada com o Ministério da Agricultura, a presidência e a administraçáo da Embrapa decidiram fundi-los em um novo portfólio de "Insumos Biológicos".

Para o Estado brasileiro e para o Programa Nacional de Bioinsumos que foi criado a partir de 2019, não há dúvida: biocontrole e biofertilizantes são uma e a mesma categoria, devendo seguir as mesmas linhas definidas pelas políticas públicas para promover seu desenvolvimento. $\mathrm{O}$ ponto culminante deste alinhamento é a disposição de não necessariamente diferenciar as duas subcategorias dentro do programa, reconhecendo que alguns produtos podem ter virtudes fertilizantes, curativas ou estimulantes para as defesas naturais das plantas.

\section{Alinhamento das problemáticas e dos usuários}

O segundo tipo de alinhamento que ocorre em torno do desenvolvimento de bioinsumos concentra-se nos problemas que os bioinsumos seriam capazes de resolver e os usuários que eles seriam capazes de satisfazer. Esse trabalho de alinhamento pode ser interpretado através do prisma da sociologia da tradução proposta por Michel Callon. O objetivo é tornar o desenvolvimento de bioinsumos um ponto de passagem obrigatório atrás do qual os diversos interesses são alinhados (CALLON, 1986), referindo-se a atores heterogêneos. Por ocasiáo da implementação do programa nacional de bioinsumos e de vários eventos relacionados ao desenvolvimento dessas tecnologias, os agentes do Ministério da Agricultura responsáveis pela implementaçáo estão tentando demonstrar que os bioinsumos estão em fase com os interesses de vários atores, para não dizer geralmente antagônicos. 


\section{Os bioinsumos, bons para tudo}

Para os promotores dos bioinsumos, eles resolveriam um grande número de problemas e criariam oportunidades em diferentes níveis geográficos ou administrativos do país. Em um país fortemente marcado por disparidades de desenvolvimento entre grandes cidades e áreas rurais negligenciadas, os bioinsumos seriam uma alavanca para o desenvolvimento local. Para o Secretário de Estado da Agricultura Familiar, responsável pelos pequenos produtores rurais, o desenvolvimento dos setores locais de bioinsumos através de "biofábricas" ajudaria a criar atividade econômica e empregos. Ele menciona o seguinte: "Na nossa opiniáo ele é um tema relevante economicamente, na própria geraçáo de renda de muitas comunidades, de muitos produtores". Enquanto hoje os territórios rurais dependem de insumos importados de países ou regióes distantes, os bioinsumos poderiam ser um ponto de partida para uma dinâmica de criaçáo de valor:

Você não tem que buscar adubo na Rússia, no Canadá ou nos Estados Unidos, o seu adubo está aqui, sua fonte de fosfatos, sua fonte de pó de rocha, seus bioinsumos estâo todos aqui, entâo o dinheiro fica todo na região, é um ciclo virtuoso.

Mas além de uma "simples" questão econômica específica de territórios remotos, os bioinsumos também são apresentados como uma questáo de soberania nacional para o Brasil. Trata-se, portanto, de utilizar o estoque nacional de recursos biológicos para reduzir a dependência do país de insumos químicos importados. Esta soberania nacional renovada é uma oportunidade para reafirmar a grandeza nacional do país, o papel central que ocuparia no mundo através da sua agricultura, e que estaria prestes a ser ainda mais consolidada através do desenvolvimento dos bioinsumos. Em seu discurso de inauguração do Programa Nacional, a Ministra da Agricultura afirma que "o Brasil é o país com a maior biodiversidade do mundo", precedendo o vídeo institucional e lembrando que o país é "o protagonista global do agronegócio, com uma produçáo que chega à mesa dos brasileiros e cidadáos de mais de 160 países, mas também com a maior biodiversidade do planeta, e um imenso banco de ativos biológicos ainda desconhecido". O líder de uma rede de agricultores que utilizam e produzem bioinsumos, o GAAS, vai ainda mais longe, dizendo que o Brasil se tornará até mesmo um dos líderes no setor dos bioinsumos:

A agricultura brasileira e vai dar exemplo para o mundo, principalmente para a América Latina (...) Vai ser um salto gigantesco tanto para a agricultura como pro Brasil, o Brasil pode se tornar a maior referência do mundo nisso e ajudar os países que estão à nossa volta Argentina, Uruguai, Paraguai, Chile... 
Mas em torno dos bioinsumos, é também um imaginário sociotécnico (JASANOFF; KIM, 2015) que se fortalece em torno da ideia de que é graças à ciência e à tecnologia que todo esse potencial, e potencial biológico, será capaz de gerar grandeza econômica ou simbólica. Como nos lembra um documento institucional que apresenta o programa, "Quando falamos de políticas para bioinsumos, estamos falando de ciência”. Este departamento sempre trabalhou com a ciência. Assim, o Programa Nacional de Bioinsumos "estimula a ciência, a tecnologia e a inovaçáo para a agricultura com infinitas opçóes”.

Atrás dos bioinsumos são, assim, chamados a se alinhar a interesses que até agora pareciam resolutamente antagônicos e compartimentalizados entre o regime dominante do agronegócio, orientado para mercados globais, e o nicho de alternativas agroecológicas orientadas para pequenos produtores em territórios esquecidos. O desenvolvimento dos bioinsumos promete reunir harmoniosamente os interesses dos territórios rurais e da nação brasileira em escala global, as questôes de emprego e distribuição igualitária da riqueza nos territórios, altos níveis de produtividade e proteção ambiental, assim como tecnologias avançadas e processos ecológicos.

\section{Bioinsumos, bons para todos os produtores}

Originalmente enraizados no nicho da agricultura orgânica e agroecológica, os insumos orgânicos têm sido considerados há muito tempo como uma alternativa para os pequenos e marginais produtores e uma alternativa ao agronegócio. Enquanto isso, os grandes produtores do regime do agronegócio continuaram a usar em massa insumos químicos. Com o desenvolvimento e a promoçáo de bioinsumos, é um alinhamento desses diferentes tipos de agricultores por trás dos bioinsumos que está sendo empreendido, promovido e parcialmente realizado.

Em primeiro lugar, o desenvolvimento de bioinsumos continua sendo, apesar da sua expansão, uma solução tecnológica para a agricultura orgânica ou agroecológica. Os funcionários responsáveis pelo Programa Nacional de Bioinsumos nunca deixam de lembrar esta origem histórica em seus discursos, a fim de sublinhar que o contato com esta parte do mundo agrícola náo é, de forma alguma, posta em questáo pelo novo impulso dado aos bioinsumos. $\mathrm{O}$ primeiro coordenador do Programa lembra regularmente no início das reunióes ou seminários que a agricultura orgânica tem desempenhado um papel pioneiro. $\mathrm{O}$ objetivo é, de fato, dar garantias aos atores deste setor para garantir que suas demandas continuem sendo consideradas e que seus valores fundadores náo sejam repudiados. Mas, além dessas garantias dadas aos pioneiros, o Ministério deve apoiar os bioinsumos numa lógica de escalamento, precisamente para garantir que essas inovaçôes saiam de seu nicho e não sejam mais limitadas ao uso que os pequenos 
produtores podem fazer delas. Para um Secretário do Ministério encarregado das políticas agrícolas dentro do Ministério, trata-se de dissociar essas tecnologias da agricultura orgânica e da ideologia que teria prevalecido até agora dentro deste nicho:

A agricultura orgânica tem que ter uma outra pegada, aproveitar esse ambiente novo do governo... o presidente (Jair Bolsonaro) tem falado de agricultura orgânica para ser uma agricultura orgânica de mercado (...) aquela coisa comunista, cubana, tem que mudar isso..., deixar a filosofia atrás... a agricultura orgânica ficou muito vinculada ao pequeno agricultor familiar, cara de assentamento, cara de assentamento.

A promoção de bioinsumos é, no entanto, parte de uma mudança ainda mais radical do que aquela que visaria converter grandes produtores para a agricultura orgânica brasileira, a qual, assim como o agronegócio, se propunha a conquistar os mercados mundiais. Os bioinsumos, como previsto, são de fato destinados a todos os agricultores, sejam eles orgânicos ou não, grandes ou pequenos. A Ministra da Agricultura deixou isso claro durante sua apresentaçáo do Programa Nacional de Bioinsumos:

Eu quero aqui dizer que nessa política todos estarão contemplados, o pessoal que trabalha orgânico há muito tempo e que sempre fez e esperou por essa política, também a agricultura comercial, que hoje já usa esse... já usa essa política, esse modelo de produção, às vezes ele puro e às vezes também ele combinado com a agricultura convencional, então acho que todos têm a ganhar, o Brasil tem a ganhar, os produtores rurais de todos os tamanhos têm a ganhar.

A força de tal discurso e das propostas para alinhar os diferentes componentes do setor rural é tanto mais forte quanto é retomada por alguns dos protagonistas históricos da agricultura orgânica, que vêm lutando há anos pelo surgimento de uma política em favor dos insumos biológicos. É o caso em particular do ex-chefe da Coordenação Nacional de Agroecologia e Agricultura Orgânica, que contribuiu ele mesmo alguns anos antes para propor o conceito de bioinsumos. Aposentado do Ministério da Agricultura, em 2019 tornou-se presidente do Instituto Brasil Orgânico, uma associação que tem como objetivo promover a agricultura orgânica no país através da conscientização, treinamento e produção de referência. Ativista de longa data contra o uso de agrotóxicos, ele vê os bioinsumos como uma alternativa tecnológica que já provou seu valor e deve ser desenvolvida para os segmentos agrícolas, muito além da agricultura orgânica: 
É muito importante que a gente entenda que essa tecnologia não serve só para agricultura orgânica, serve para todos os produtores.

É a implementaçáo dessa exigência que alguns ativistas do GAAS estão colocando em prática, indo ainda mais além da defesa do uso "simples" de bioinsumos. De fato, com o apoio dos pesquisadores da Embrapa em particular, eles estão defendendo o direito de todos os produtores, náo importando quão grandes ou pequenos, de produzir seus próprios bioinsumos. Enquanto esta demanda estava originalmente associada às esferas alternativas da agroecologia e dos pequenos produtores, os agricultores do GAAS também não hesitam em fazer dos bioinsumos o símbolo de uma busca por emancipação e soberania. Para seu coordenador,

É dar soberania para o agricultor, o agricultor precisa voltar a ser dono do negócio dele, que que acontece na agricultura hoje? $\mathrm{O}$ agricultor está refém de um crédito agrícola, tá refém de uma multinacional que tem que dar um insumo para ele, tem que dar o crédito, tem que dar o insumo, ele acaba ficando amarrado nesse sistema e não consegue sair do sistema químico tradicional às vezes.

No mesmo espírito, enquanto a defesa do conhecimento tradicional parecia estar resolutamente inscrita no nicho das agriculturas alternativas, em oposição ao regime agroindustrial, o GAAS também se posiciona com o direito de produzir seus próprios insumos em linha com uma reabilitaçáo de certos direitos ou aptidôes ou de produtores.

A gente faz uma agricultura moderna, mas à moda antiga, né? Como os nossos avós faziam, como nossos bisavós, né? A gente está tentando trazer isso para a realidade pra grande escala, né?

Por trás dos bioinsumos e sua apropriação pelos produtores, uma forma de continuidade e alinhamento histórico está sendo planejada. Trata-se de convidar os agricultores de hoje e de amanhã a seguir os passos dos do passado para recuperar formas de independência e soberania que se teriam perdido, sem negar os avanços contemporâneos na ciência e na tecnologia. Nesse passado idealizado, os agricultores eram uma e a mesma coisa, formando um todo homogêneo que teria sido posteriormente dividido. Esta visão de um passado que precisa ser restaurado também leva à ideia de que, naquela época, os agricultores eram um grupo indiferenciado, pelo menos poupado de algumas das fraturas que o atravessam hoje. Para o coordenador do GAAS, os bioinsumos constituem hoje um conjunto 
de tecnologias subjacentes que são chamados a alinhar todos os componentes do setor agrícola:

É um grupo que junta todas as agriculturas que existem. Hoje a gente fala de biodinâmica, agricultura orgânica, fala de agricultura sintrópica, fala de agroecologia, fala de agricultura convencional. é o modelo que serve desde o plantador de alface, de quiabo lá com seu meio hectare, até o grande mega produtor... a gente já deixa bem claro, a gente não fala mal de nenhuma agricultura, a gente é o caminho do meio.

Assim, embora os bioinsumos tenham emergido do alinhamento dentro de uma única categoria de várias tecnologias, tanto do nicho agroecológico como do regime agronegócio, seu desenvolvimento e promoção dentro da comunidade agrícola e da sociedade em geral também dependem do alinhamento de uma diversidade de interesses e usuários, eles próprios previamente polarizados. Um terceiro nível de convergência e alinhamento apoiando o desenvolvimento de bioinsumos finalmente ocorre, como veremos na próxima seção, no nível das instituiçôes públicas encarregadas de supervisionar o setor agrícola.

\section{Os bioinsumos no coração da reorganização político-institucional}

Os bioinsumos surgiram formalmente pela primeira vez no cenário administrativo brasileiro durante a elaboração do Planapo 2, quando Dilma Rousseff ainda estava no poder. Desde então, a infraestrutura político-institucional encarregada de promover e gerenciar esses bioinsumos evoluiu consideravelmente, tendo também passado por mecanismos de reorganização bastante radicais. Como mencionado anteriormente, a polarização entre o nicho da agricultura alternativa e o regime agronegócio náo foi simplesmente uma questão de oposição entre tecnologias. De fato, são as formas de atividade agrícola e os modelos agrários que se opóem, por um lado, aos pequenos produtores familiares enraizados nos territórios e, por outro lado, aos grandes produtores e a uma agricultura financeiramente orientada para os mercados globais. Embora essa polarização náo seja táo clara entre a população rural (NIEDERLE, 2018), ela encontrou uma clara traduçáo no Brasil dentro de um aparato estatal dualista, caracterizado pela existência entre 2000 e 2016 de dois ministérios encarregados das questôes agrícolas. A agricultura familiar entrou formalmente no cenário institucional em 1996, com a criaçáo do Programa Nacional de Fortalecimento da Agricultura Familiar (PRONAF), destinado a apoiar as famílias responsáveis pelas pequenas unidades de produção 
agrícola (FLEXOR; GRISA, 2016). Essa criação foi feita em resposta às repetidas demandas dos movimentos sociais ligados aos trabalhadores rurais, que, com o retorno da democracia em meados dos anos 1980, ganharam influência política em torno de causas como a reforma agrária. Neste espírito, o Ministério da Agricultura passou por uma primeira evolução, tornando-se o Ministério da Agricultura, Abastecimento e Reforma Agrária. Mas foi em 2000 que ocorreu uma inovação institucional radical com a criação do MDA, encarregado das questóes relacionadas aos pequenos produtores e à reforma agrária, enquanto o Ministério original se tornou o Ministério da Agricultura, Pecuária e Abastecimento. Este dualismo, que nos anos 2000 inspiraria outros países da regiáo, como a Argentina (GOULET, 2020), traz o dualismo agrário brasileiro para o topo da infraestrutura estatal e dá ao país uma visibilidade particular no cenário internacional no que diz respeito às políticas de apoio às populaçóes rurais mais pobres. Precisamente dentro do MDA seria criada a Coordenação Nacional de Agroecologia e Agricultura Orgânica, desempenhando um papel fundamental para colocar o conceito de bioinsumos na agenda política.

O impeachment contra Dilma Rousseff marca o fim radical desta política dualista: o MDA é literalmente apagado do mapa institucional. Todos os projetos associados à agroecologia ou à agricultura familiar são interrompidos ou deixam de ser financiados, e as equipes da MDA estão dispersas dentro do MAPA. Uma Secretaria da Agricultura Familiar é criada neste último, e mantida em 2019, quando o governo Bolsonaro chega. Entretanto, não é dentro dessa Secretaria que o governo Bolsonaro cria o Programa Nacional de Bioinsumos em 2019. Seu desenvolvimento está de fato confiado à Coordenação Geral de Novos Insumos e Serviços, sob o Departamento de Inovação para Agricultura e Pecuária dentro da novíssima Secretaria de Inovação, Desenvolvimento Rural e Irrigação. Para assumir a liderança na implementação do programa, uma pessoa de fora do Ministério é convidada a se juntar ao Ministério, na pessoa de um cientista da Embrapa, especialista em macro-organismos utilizados no controle biológico em produção de hortaliças.

Desde o início, o grupo de trabalho que está desenvolvendo o programa desde 2019 está posicionado na intersecção entre os diferentes departamentos do Ministério. Embora seja dirigida pela Secretaria de Inovação, Desenvolvimento Rural e Irrigação, também inclui representantes da Secretaria de Proteção Agrícola, encarregados da avaliaçáo e registro de insumos, da Secretaria de Políticas Agrícolas e da Secretaria de Agricultura Familiar e Cooperativismo. Este desejo de colocar bioinsumos no cruzamento dessas diferentes unidades institucionais torna-se claro em maio de 2019, quando um seminário foi organizado no MAPA para lançar oficialmente o GT e informar os diferentes departamentos do 
Ministério sobre esta iniciativa. Nada menos que três secretários (ou secretários adjuntos) do Ministério foram convidados ao pódio para abrir o seminário: o Secretário Adjunto de Inovação, Desenvolvimento Rural e Irrigação, o Secretário de Agricultura Familiar e o Secretário de Aquicultura e Pesca. Os três funcionários insistiram, então, em seus discursos de abertura sobre o símbolo de alinhamento - que é o termo que eles usaram - que os bioinsumos representariam no novo panorama institucional interno do DAFA. O Secretário Adjunto de Inovaçáo, Desenvolvimento Rural e Irrigaçáo se refere a um "tema muito transversal: a agricultura brasileira precisa desta contribuiçáo, precisa deste fortalecimento", enquanto o Secretário de Agricultura Familiar relata sua "satisfação em trabalhar em alinhamento com todas as secretarias aqui no Ministério da Agricultura”, e o Secretário de Aquicultura e Pesca considera "muito importante este alinhamento que vimos nos últimos meses, com este novo desenvolvimento da Esplanada dos Ministérios". Bioinsumos são, assim, apresentados como um símbolo da reorganização institucional que começou em 2016 com o desaparecimento do MDA: para o Estado brasileiro, existe agora formalmente apenas uma agricultura, apesar das nuances representadas nas secretarias, encarnadas por um único Ministério. Em maio de 2020, para a inauguração do Programa Nacional de Bioinsumos, a Ministra inicia seu discurso reposicionando os bioinsumos no âmbito deste novo alinhamento institucional:

Um momento muito especial que é o lançamento da Política de Bioinsumos do Ministério da Agricultura do Brasil, é uma satisfação enorme poder, como Ministra da Agricultura, estar aqui nesse momento quando o Ministério da Agricultura que hoje é um só ministério que trouxe pra cá todas as políticas agrícolas do Brasil, o ministério que recebeu hoje temos aqui o pequeno, o médio e o grande produtor rural. (...) nós estamos alinhando a necessidade da inovação no segmento agrícola, aquícola, florestal e pecuário.

Os bioinsumos, que são o resultado do alinhamento de tecnologias e visóes que se enquadram no nicho das alternativas agroecológicas, bem como do sistema agroindustrial, são, portanto, parte de uma transformaçáo institucional que também se enquadra na mesma lógica de alinhamento.

\section{Conclusões}

Neste capítulo, mostramos como o Estado brasileiro tem se empenhado nos últimos anos, e ao longo das mudanças políticas, para promover tecnologias alternativas aos insumos químicos. Vimos que as políticas e instrumentos definidos desde 2018, com o Programa Nacional de Bioinsumos, não preveem o desenvolvimento 
de bioinsumos em uma lógica de ruptura tecnológica ou substituição. Em uma lógica de transiçáo, e a fim de permitir que os atores do regime dominante se adaptem, o desafio é antes organizar uma coexistência entre as tecnologias, e mais amplamente entre os modelos agrários. Embora essas políticas apoiem parcialmente as demandas de longa data dos movimentos agroecológicos, elas também contribuem para despolitizar a questáo do uso de insumos químicos e suas alternativas, o que é uma questão sensível para os atores dominantes no setor do agronegócio. Bioinsumos seriam assim tecnologias para todos, tornando possível resolver diversos problemas e satisfazer interesses contraditórios, e não questionando o atual equilíbrio de poder dentro do setor rural. Obviamente, essa abordagem consensual para o desenvolvimento de alternativas aos insumos químicos está politicamente situada, e as orientaçóes podem ser redefinidas de acordo com a alternância política. Além disso, é uma abordagem federal, dando linhas gerais definidas independentemente das singularidades políticas, econômicas, sociais ou políticas dos estados e territórios do Brasil. O desenvolvimento de tais tecnologias nos territórios semiáridos do Nordeste, por exemplo, coloca, como este livro nos lembra, desafios específicos para a produçáo, transporte ou utilizaçáo de tais insumos vivos. Mas o desenvolvimento local e a produção de insumos orgânicos abrem uma oportunidade para reduzir a dependência de insumos externos, cuja produçáo e transporte contribuem para o aquecimento global. Por esse motivo, o estudo das condiçóes para o desenvolvimento dessas inovaçóes tecnológicas no Nordeste nos próximos anos é um objeto de pesquisa importante e uma alavanca necessária para a implementação e adaptação de políticas federais que possam contribuir para o desenvolvimento sustentável do semiárido nordestino.

\section{Referências}

ALBIERO, D.; MENDES CAJADO, D.; CARVALHO FERNANDES, I. L.; ALMEIDA MONTEIRO, L.; GALGANI SILVEIRA LEITE ESMERALDO, G. (Orgs.). Tecnologias agroecológicas para o Semiárido. Fortaleza: Edição do Autor, 2015.

ALTIERI, M. A.; ROSSET, P. M.; NICHOLLS, C. I. Biological Control and Agricultural Modernization: Towards Resolution of Some Contradictions. Agriculture and Human Values, v. 14, n. 3, p. 303-310, 1997. doi: 10.1023/A:1007499401616.

AUlAGNIER, A.; GOUlET, F. Des technologies problématiques et de leurs alternatives. Le cas des pesticides agricoles en France. Sociologie du Travail, v. 59, n. 3, 2017. doi: https://doi. org/10.4000/sdt.840.

BOWKER, G.; LEIGH STAR, S. Sorting Things Out. Classification and Its Consequences. Cambridge, MA, London: The MIT Press, 1999.

CALLON, M. Some Elements of a Sociology of Translation: Domestication of the Scallops and the Fishermen of the St Brieuc Bay. In: LAW, J. (Org.). Power, Action and Belief: A New Sociology of Knowledge? London: Routledge, 1986. p. 196-223. 
DELVENNE, P.; HENDRICKX, K. The Multifaceted Struggle for Power in the Bioeconomy: Introduction To the Special Issue. Technology in Society, v. 35, n. 2, p. 75-78, 2013. doi: https://doi. org/10.1016/j.techsoc.2013.01.001.

FLEXOR, G.; GRISA, C. Contention, Ideas, and Rules: The Institutionalization of Family Farm Policy in Brazil. Canadian Journal of Latin American and Caribbean Studies, v. 41, n. 1, p. 23-37, 2016. doi: 10.1080/08263663.2015.1130292.

GEELS,, F.W. Technological Transitions as Evolutionnary Reconfiguration Processes: A Multi-Level Perspective and a Case Study. Research Policy, v. 31, p. 1257-74, 2002.

GOULET, F. Family Farming and the Emergence of an Alternative Sociotechnical Imaginary in Argentina. Science, Technology and Society, v. 25, n. 1, p. 86-105, 2020. doi: $10.1177 / 0971721819889920$.

GOULET, F.; HUBERT, M. Making a Place for Alternative Technologies: The Case of Agricultural Bio-Inputs in Argentina. Review of Policy Research, v. 37, n. 4, p. 535-55, 2020. doi: https://doi. org/10.1111/ropr.12384.

GOULET, F; AULAGNIER, A.; HUBERT, M. Del reemplazo tecnológico al desplazamiento de fronteras: las alternativas a los agroquímicos en Argentina, Brasil y Francia. In: MOMBELLO, L.; SPIVAK L'HOSTE, A. (Org.). Naturaleza y conocimientos en tensión. Buenos Aires: Editorial Teseo, 2020. p. 279-299.

GUICHARD, L.; DEDIEU, F.; JEUFFROY, M. H.; MEYNARD, J. M.; REAU, R.; SAVINI, I. Le Plan Ecophyto de réduction d'usage des pesticides en France: décryptage d'un échec et raisons d'espérer.

Cahiers Agricultures, v. 26, n. 1, p. 14002, 2017.

JASANOFF, S.; KIM, S. H. (Orgs.). Dreamscapes of Modernity: Sociotechnical Imaginaries and the Fabrication of Power. Chicago: Chicago University Press, 2015.

MACÊDO JORGE, D.; VAZ DE SOUZA, C. A. O Papel da Regulamentação dos Produtos de Origem Biológica no Avanço da Agroecologia e da Produção Orânica no Brasil. In: ROSA SAMBUICHI, R. H.; FERREIRA DE MOURA, I.; MANSOR DE MATTOS, L.; DE ÁVILA, M. L.; ASAFE CAMPOS SPÍNOLA, P.; MOREIRA DA SILVA, A. P. (Orgs.). A Política Nacional de Agroecologia e Produçáo Orgânica no Brasil: Uma Trajetória de Luta pelo Desenvolvimento Rural Sustentável. Brasília: IPEA, 2017.

NIEDERLE, P. A. A Pluralist and Pragmatist Critique of Food Regime's Genealogy: Varieties of Social Orders in Brazilian Agriculture. The Journal of Peasant Studies, v. 45, n. 7, p. 1460-83, 2018. doi: 10.1080/03066150.2017.1313238.

STEGMAIER, P.; KUHLMANN, S.; VISSER, V. R. The Discontinuation of Socio-Technical Systems as a Governance Problem. In: BORRAS, S.; EDLER, J. (Orgs.). The Governance of Socio-Technical Systems. Cheltenham: Edward Elgar, 2014. p. 111-31. 